\title{
CRESCIMENTO E ASPECTOS SINTOMATOLÓGICOS NA ACLIMATIZAÇÃO DE IPÊ-ROXO
}

\author{
João Paulo Rodrigues Martins ${ }^{1}$, Breno Régis Santos², Sandro Barbosa³, Wesley Pires Flausino Máximo4, \\ Luiz Alberto Beijo ${ }^{5}$, Renato Paiva ${ }^{6}$
}

(recebido: 7 de dezembro de 2009; aceito: 30 de junho de 2011)

RESUMO: Este trabalho teve por objetivo avaliar a influência do tipo de vedação e substrato na pré-aclimatização e os aspectos sintomatológicos na aclimatização de Ipê-roxo. Para pré-aclimatização, plantas de Ipê-roxo obtidas in vitro por meio de cultura de embriões zigóticos foram inoculadas assepticamente em tubos de ensaio contendo diferentes tipos de vedação (algodão, tampa plástica + parafilme e tampa plástica) e diferentes substratos (ágar, vermiculita e Plantmax ${ }^{\circledR}$ ) suplementados com meio de cultivo WPM acrescidos de $1 \mathrm{gL}^{-1}$ de carvão ativado, $10 \mathrm{mgL}^{-1}$ de ácido cítrico e $30 \mathrm{gL}^{-1}$ de sacarose. Para a aclimatização, plantas de Ipê-roxo obtidas in vitro foram transplantadas para tubetes de $56 \mathrm{~cm}^{3}$, contendo vermiculita e Plantmax ${ }^{\circledR}$ na proporção $2: 1$, previamente autoclavado a $121^{\circ} \mathrm{C}$ e $1 \mathrm{~atm}$, por 20 minutos. Após o transplantio, as plantas foram irrigadas com diferentes concentrações do meio MS (25\%, 50\%, 75\%, $100 \%$ e 150\%), sendo utilizada como controle água destilada. Após 30 dias, foram verificados efeitos do tipo de vedação e substrato na pré-aclimatização. O algodão pode ser recomendado quando se utiliza Plantmax ${ }^{\circledR}$ ou vermiculita como substrato. Na aclimatização, verificou-se que as plantas quando irrigadas com água destilada e concentrações $\leq 50 \%$ apresentaram sintomas de deficiência nutricional. Foram observados sintomas semelhantes com a utilização de MS em concentração igual ou superior a 100\%. A concentração $75 \%$ do meio MS foi a mais eficiente na manutenção do vigor nutricional de mudas de Ipê-roxo em processo de aclimatização.

Palavras-chave: Handroanthus impetiginosus, pré-aclimatização, cultura de tecidos, vedação.

\section{GROWTH AND SYMPTOMATOLOGICAL ASPECTS IN THE ACCLIMATIZATION OF IPÊ-ROXO}

ABSTRACT: This work evaluated the influence of seal type and substrate type on pre-acclimatization, and symptomatological aspects relating to acclimatization of ipê-roxo. For the pre-acclimatization, ipê-roxo plants obtained through an in vitro zygotic embryo culture were aseptically inoculated in test tubes with different types of seal (cotton plug, plastic cap + parafilm and plastic lid) and different substrates (agar, vermiculite and Plantmax ${ }^{\mathbb{B}}$ ) supplemented with a WPM culture medium with $1 \mathrm{gL}^{-1}$ of activated charcoal, $10 \mathrm{mgL}^{-1}$ of citric acid and $30 \mathrm{gL}^{-1}$ of sucrose added. For the acclimatization, in vitro ipe-roxo plants were transplanted into 56 -cm ${ }^{3}$ plastic tubes containing vermiculite and Plantmax ${ }^{\circledR}$ at a $2: 1$ ratio which had been previously autoclaved at $121^{\circ} \mathrm{C}$ and 1 atm for 20 minutes. Once transplanted, the plants were irrigated with different concentrations of the MS medium $(25 \%, 50 \%, 75 \%, 100 \%$ and $150 \%)$, using distilled water as control. After 30 days, the effects of seal type and substrate type on pre-acclimatization were examined. Cotton can be recommended where Plantmax ${ }^{\circledR}$ or vermiculite is used as substrate. In the acclimatization it was noted that where plants were irrigated with distilled water and concentrations $\leq 50 \%$ they showed symptoms of nutritional deficiency. Similar symptoms were observed when using MS medium at a concentration equal to or greater than $100 \%$. The $75 \%$ MS concentration was found to be the most effective at maintaining the nutritional vigor of ipê-roxo seedlings in the process of acclimatization.

Key words: Handroanthus impetiginosus, pre-acclimatization, tissue culture, seal.

\section{INTRODUÇÃO}

O Ipê-roxo [Handroanthus impetiginosus (Mart. Ex DC) Mattos], recentemente incluído no gênero Handroanthus, é uma espécie arbórea pertencente à família Bignoniaceae (GROSE; OLMSTEAD, 2007), podendo ser comumente encontrado em áreas de vegetação nativa do Nordeste e Sudeste brasileiro. Essa árvore é muito apreciada e utilizada na fabricação de móveis e assoalhos finos, além de apresentar propriedades farmacológicas com ação antiinflamatória, analgésica, antibiótica e antineoplásica. Essa espécie foi intensamente explorada

\footnotetext{
${ }^{1}$ Bacharel em Ciências Biológicas, Mestrando em Agricultura Tropical - Universidade Federal do Espírito Santo - Centro Universitário Norte do Espírito Santo - Rodovia BR 101 Norte, Km. 60 - 29932-540 - São Mateus, ES - jprmartinss@yahoo.com.br

${ }^{2}$ Engenheiro Agrônomo, Professor, Dr. em Fisiologia Vegetal - Instituto de Ciências da Natureza/ICN - Universidade Federal de Alfenas/UNIFAL-MG Rua Gabriel Monteiro da Silva, 700 - 37130-000 - Alfenas, MG - brenors@yahoo.com.br

${ }^{3}$ Biólogo, Professor, Dr. em Genética e Melhoramento de Plantas - Instituto de Ciências da Natureza/ICN - Universidade Federal de Alfenas/ UNIFAL-MG - Rua Gabriel Monteiro da Silva, 700 - 37130-000 - Alfenas, MG - sandro.barbosa@unifal-mg.edu.br

${ }^{4}$ Graduando em Biotecnologia - Instituto de Ciências da Natureza/ICN - Universidade Federal de Alfenas/UNIFAL-MG - Rua Gabriel Monteiro da Silva, 700 - 37130-000 - Alfenas, MG - wesleypfm@hotmail.com

${ }^{5}$ Matemático, Professor, Dr. em Estatística e Experimentação Agropecuária - Instituto de Ciências Exatas/ICE - Universidade Federal de Alfenas/ UNIFAL-MG - Rua Gabriel Monteiro da Silva, 700 - 37130-000 - Alfenas, MG - luizbeijo@yahoo.com.br

${ }^{6}$ Engenheiro Agrônomo, Professor, PhD em Agronomia - Departamento de Biologia/DBI - Universidade Federal de Lavras/UFLA - Cx. P. 37 37200-000 - Lavras, MG - renpaiva@dbi.ufla.br
}

Cerne, Lavras, v. 17, n. 4, p. 435-442, out./dez. 2011 
nas regiões de ocorrência natural, restando poucas árvores isoladas, justificando sua inclusão em trabalhos de restauração de ecossistemas florestais e de paisagismo (GEMAQUE et al., 2002).

As técnicas de cultivo in vitro podem ser utilizadas como instrumento para multiplicação de espécies vegetais ameaçadas de extinção. Nesse sentido, tem-se observado um aumento nos estudos das técnicas de micropropagação nos últimos anos e é provável que essa tendência se mantenha, uma vez que diversas espécies que enfrentam risco de extinção necessitam de um aumento na demanda de propagação (SARASAN et al., 2006). Dessa forma, a micropropagação apresenta-se como alternativa viável para a produção de mudas de Handroanthus spp., auxiliando na restauração de vegetações degradadas e no paisagismo.

Porém, um número expressivo de espécies vegetais micropropagadas não sobrevive quando transferidas das condições in vitro para o ambiente de casa de vegetação ou campo (HARARIKA, 2003). Ao sofrer mudança abrupta de ambiente, ou seja, passando de condições in vitro para ex vitro, normalmente as plantas apresentam uma parada ou redução do crescimento até que se adaptem às novas condições, podendo levar dias até semanas para retomarem o crescimento (PEREIRA et al., 2001; PEREIRA; FORTES, 2000). Procedimentos eficientes de pré-aclimatização podem contribuir para elevar a taxa de sobrevivência, evitando que as plantas se desidratem e murchem durante e após o transplantio (VILLA et al., 2006).

Esta etapa compreendida entre a transferência de plantas cultivadas em condições assépticas para o ambiente externo constitui uma fase fundamental na produção de mudas obtidas por micropropagação, uma vez que as condições de cultivo in vitro modificam suas características bioquímicas, anatômicas e morfológicas, alterando os processos fisiológicos normais (LUCAS et al., 2002; PEREIRA; FORTES, 2001).

Neste trabalho, objetivou-se avaliar a influência do tipo de substrato e vedação dos tubos de ensaio na préaclimatização e a suplementação nutricional de plantas de Ipê-roxo durante a fase de aclimatização, com intuito de obter plantas de qualidade ao final de todo o processo.

\section{MATERIAL E MÉTODOS}

Para o cultivo in vitro foram utilizados como explantes embriões retirados de sementes de Ipê-roxo. A assepsia dos embriões foi realizada por meio de imersão em hipoclorito de sódio $1 \%(\mathrm{~m} / \mathrm{v})$ de cloro ativo por
10 minutos e, em seguida, lavados com água destilada autoclavada por três vezes. Após a desinfestação, os explantes foram inoculados em meio de cultura sem suplementação salina, contendo $30 \mathrm{gL}^{-1}$ de sacarose, $6 \mathrm{gL}^{-1}$ de ágar e $1 \mathrm{gL}^{-1}$ de carvão ativado, sendo o pH ajustado em 5,8 antes da autoclavagem a $121^{\circ} \mathrm{C}$, durante 20 minutos.

Para a avaliação do efeito do tipo de substrato e vedação na pré-aclimatização, plantas de Ipê-roxo com 45 dias de cultivo in vitro foram transferidas assepticamente para tubos de ensaio contendo diferentes tipos de vedação (algodão, tampa plástica+parafilme e tampa plástica) e diferentes substratos ágar, vermiculita e Plantmax ${ }^{\circledR}$ sendo esse último um substrato comercial, químico, físico, biologicamente estabilizado e pronto para uso. Os substratos foram suplementados com meio Woody Plant Medium (WPM) segundo metodologia proposta por Lloyd e McCown (1981) acrescido de $1 \mathrm{gL}^{-1}$ de carvão ativado, $10 \mathrm{mgL}^{-1}$ de ácido cítrico e $30 \mathrm{gL}^{-1}$ de sacarose, sendo o $\mathrm{pH}$ ajustado para 5,8 antes da autoclavagem a $121^{\circ} \mathrm{C}$, durante 20 minutos. $\mathrm{O}$ experimento foi conduzido em delineamento inteiramente casualizado (DIC) em esquema fatorial $3 \times 3$ (três substratos e três tipos de vedação). $\mathrm{O}$ experimento constou de 5 repetições, contendo 5 tubos de ensaio por repetição. A avaliação foi realizada após 30 dias observando altura da planta, número de folhas e o comprimento longitudinal da folha referente ao primeiro nó, as quais foram classificadas em três grupos diferentes de acordo com os parâmetros estipulados: 1 - menor que $0,6 \mathrm{~cm} ; 2-0,6$ a 2,0 cm; e 3 - maior que 2,0 $\mathrm{cm}$.

Para o estudo nutricional durante a aclimatização, plantas de Ipê-roxo provenientes do cultivo in vitro foram transplantadas para tubetes de $56 \mathrm{~cm}^{3}$, contendo vermiculita e Plantmax ${ }^{\circledR}$ na proporção 2:1, previamente autoclavados a $121^{\circ} \mathrm{C}$ por 20 minutos. Após o transplantio, as plantas foram irrigadas duas vezes por semana com 10 $\mathrm{mL}$ das concentrações $25 \%, 50 \%, 75 \%, 100 \%$ e $150 \%$ do meio MS (MURASHIGE; SKOOG, 1962), sendo usada água destilada como tratamento controle. Os tubetes foram cobertos com sacos plásticos e umidificados com água destilada. A cada 10 dias, uma das extremidades dos sacos plásticos foi cortada e, ao fim de 30 dias, esses foram retirados.

$\mathrm{O}$ experimento foi conduzido em DIC contendo 5 repetições, sendo cada parcela composta por 5 plantas. A avaliação foi realizada em dois tempos, aos 20 e 40 dias após o transplantio, sendo analisado o crescimento no intervalo de avaliação, tomando a diferença entre a altura obtida aos 40 e 20 dias, diferença do número médio

Cerne, Lavras, v. 17, n. 4, p. 435-442, out./dez. 2011 
de folhas entre as avaliações e aspecto sintomatológico nutricional por meio de notas de $1 \mathrm{a} 4$. Para estas, foram adotados os critérios mencionados por Leal e Prado (2008) e Prado et al. (2007), classificando-as em quatro grupos: 1 - sintomatologia de deficiência nutricional severa, apresentando necrose apical, alto índice de abscisão foliar, necrose em quase a totalidade do limbo foliar, clorose intensa do limbo foliar, coloração pouco intensa do caule e folhas, ausência de folhas compostas; 2 - sintomatologia de deficiência nutricional intermediária, apresentando necrose internerval nas folhas, clorose foliar, coloração desuniforme das folhas e caule, ausência de folhas compostas; 3 - sintomatologia de deficiência nutricional pouco aparente, apresentada pela coloração de folhas e caule, ausência de folhas compostas; 4 - sintomatologia de deficiência nutricional ausente, presença de folhas compostas.

Em todos os procedimentos experimentais acima descritos os explantes foram mantidos em sala de crescimento sob irradiância de $43 \mu \mathrm{mol} \cdot \mathrm{m}^{-2} \cdot \mathrm{s}^{-1}$ a $25 \pm 2^{\circ} \mathrm{C}$ e fotoperíodo de 12 horas, após a inoculação.

Os dados foram submetidos à análise de variância com auxílio do software Sisvar 4.3 (FERREIRA, 1999) e as médias comparadas utilizando o teste de Scott-Knott para as variáveis referentes à pré-aclimatização, aos aspectos sintomatológicos nutricionais e ao crescimento das plantas dentro do intervalo de avaliação, e regressão para diferença no número médio de folhas entre as avaliações.

\section{RESULTADOS E DISCUSSÃO}

De acordo com a análise de variância - ANAVA (Tabela 1), verificou-se que o substrato combinado com o tipo de vedação influenciou significativamente no comprimento das folhas e na altura das plantas de Ipê-roxo, sendo o número de folhas influenciado apenas pelo tipo de vedação utilizado.

Pereira et al. (2005) afirmam que a fase de pré-aclimatização não pode ser omitida, pois as novas condições devem ser repassadas às plantas de forma progressiva. Nascimento et al. (2008) observaram que o período de pré-aclimatização em plantas de Uvaieira (Eugenia pyriformis Cambess) aumentou a proporção de sobrevivência na aclimatização.

Observou-se que o tipo de vedação do tubo de ensaio, combinado com o tipo de substrato, influenciou significativamente na altura das plantas. Os tratamentos que empregaram algodão, combinado com Plantmax ${ }^{\circledR}$ ou vermiculita, obtiveram os melhores resultados (Tabela 2).
Tabela 1 - ANAVA para a altura (ALT), número médio de folhas (NMF) e comprimento médio da folha (CMF) para Ipê-roxo após 30 dias de pré-aclimatização.

Table 1 - ANAVA for height (ALT), average number of leaves (NMF) and average leaflength (CMF) for ipê-roxo after 30 days of pre-acclimatization.

\begin{tabular}{lcccc}
\hline \multirow{2}{*}{ Fonte de Variação } & \multirow{2}{*}{$\begin{array}{c}\text { Grau de } \\
\text { Liberdade }\end{array}$} & \multicolumn{3}{c}{ Quadrado Médio } \\
\cline { 3 - 5 } & 2 & $41,67^{* *}$ & $2,60^{* *}$ & $4,68^{* *}$ \\
\hline Vedação & 2 & 5,42 & 4,83 & $0,76^{*}$ \\
Substrato & 4 & $9,57^{* *}$ & 3,67 & $0,74^{* *}$ \\
Vedação x Substrato & 36 & 2,44 & 1,70 & 0,17 \\
Erro & & 20,99 & 30,90 & 24,59 \\
Coeficiente de & & & & \\
Variação(\%) & &
\end{tabular}

* Significativo ao nível de 5\%. ** Significativo ao nível de 1\%.

Tabela 2 - Altura das plantas de Ipê-roxo $(\mathrm{cm})$ em função do tipo de substrato combinado com tipo de vedação na préaclimatização.

Table 2-Height of ipe-roxo plants (cm) as a function of substrate type combined with seal type in pre-acclimatization.

\begin{tabular}{lccr}
\hline Substrato/Vedação* & $\begin{array}{c}\text { Tampa } \\
\text { plástica }\end{array}$ & $\begin{array}{c}\text { Tampa plástica } \\
+ \text { parafilme }\end{array}$ & Algodão \\
\hline Ágar & $6,21 \mathrm{Aa}$ & $6,92 \mathrm{Aa}$ & $7,15 \mathrm{Ab}$ \\
Vermiculita & $7,80 \mathrm{Ba}$ & $5,66 \mathrm{Ca}$ & $10,25 \mathrm{Aa}$ \\
Plantmax $^{\circledR}$ & $6,20 \mathrm{Ba}$ & $6,14 \mathrm{Ba}$ & $10,63 \mathrm{Aa}$ \\
\hline
\end{tabular}

*Teste de Scott-Knott com significância de 5\%, médias seguidas de mesma letra minúscula na coluna e maiúscula na linha não diferem estatisticamente entre si.

Segundo Smiderle et al. (2001), o Plantmax ${ }^{\circledR}$ possui composição química bem balanceada, contendo principalmente os nutrientes $\mathrm{N}, \mathrm{P}, \mathrm{K}, \mathrm{Ca}$ e $\mathrm{Mg}$. Costa et al. (2009) mencionam que a vermiculita apresenta grande capacidade de aeração e retenção de água, o que propicia um melhor desenvolvimento do sistema radicular, afirmações essas que corroboram com os resultados obtidos neste trabalho.

Dentro dos tratamentos que utilizaram algodão na vedação do tubo de ensaio, o que empregou ágar como substrato foi o que apresentou a menor média para altura $(7,15 \mathrm{~cm})$. Mills et al. (2004) afirmaram que em um sistema de ambientes com maior transpiração obtêm-se melhor desenvolvimento do sistema vascular, que é o responsável pela distribuição dos fitohormônios como a auxina. Esta é capaz de iniciar a divisão celular e controlar os processos de crescimento e elongação celular (NOGUEIRA et al., 2007).

Cerne, Lavras, v. 17, n. 4, p. 435-442, out./dez. 2011 
Bellintani et al. (2007) mencionaram que a vantagem do selamento com algodão em relação ao método de fechamento tradicional demonstra que as trocas gasosas, entre o microambiente in vitro e o ambiente externo, favorecem o desenvolvimento de adaptações contra a perda de água por transpiração. Damiani e Schuch (2009) afirmaram que o aumento das trocas gasosas com o uso de um sistema de vedação mais permeável a gases atua de forma positiva no desenvolvimento da planta, em razão da redução do efeito tóxico provocado pelo acúmulo de etileno nos frascos de cultivo.

Para a variável número de folhas, apenas o tipo de vedação influenciou de forma significativa, sendo os três tratamentos diferentes entre si pelo teste Scott-Knott. O tratamento que empregou tampa plástica sem parafilme obteve o maior número de folhas, seguida pelo algodão, sendo tampa plástica+parafilme o menor (Figura 1).

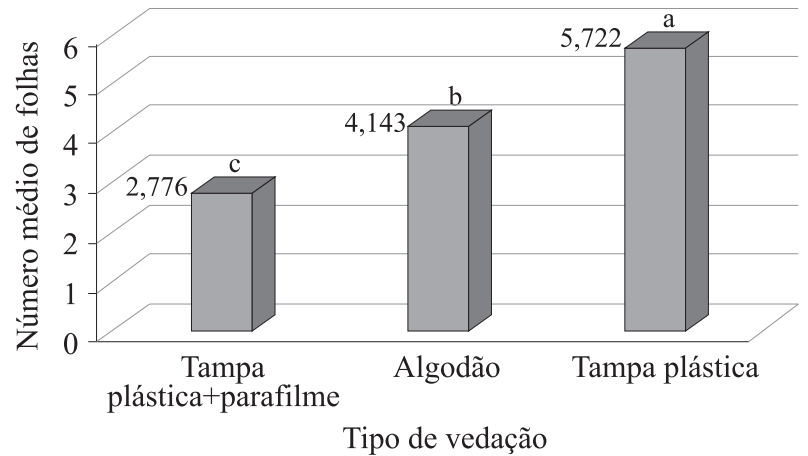

Figura 1 - Número médio de folhas em relação ao tipo de vedação em pré-aclimatização de Ipê-roxo. Letras diferentes diferem estatisticamente segundo teste de Scott-Knott ao nível 5\%.

Figure 1 - Average number of leaves in relation to seal type in pre-acclimatization of ipê-roxo. Different letters differ statistically by the Scott-Knott test at the 5\% level.

Esses resultados estão de acordo com Nepomuceno et al. (2009) e Zobayed et al. (2000), que observaram, respectivamente, maiores médias do número de folhas em Angico-branco (Anadenanthera colubrina) e Eucalyptus camaldulensis quando os tubos de ensaio foram vedados com tampa plástica sem parafilme.

Foi observado que o comprimento da folha em plantas de Ipê-roxo em pré-aclimatização apresentou diferença significativa na interação substrato x vedação, sendo os tratamentos com algodão combinados com Plantmax ${ }^{\circledR}$ ou vermiculita com maior comprimento médio (Tabela 3).

Cerne, Lavras, v. 17, n. 4, p. 435-442, out./dez. 2011
Tabela 3 - Média do comprimento $(\mathrm{cm})$ da folha em função do substrato combinado com tipo de vedação na pré-aclimatização de plantas de Ipê-roxo.

Table 3 -Average leaf length $(\mathrm{cm})$ as a function of substrate type combined with seal type in pre-acclimatization of ipê-roxo plants.

\begin{tabular}{lccc}
\hline Substrato/Vedação* & $\begin{array}{c}\text { Tampa } \\
\text { plástica }\end{array}$ & $\begin{array}{c}\text { Tampa plástica } \\
\text { + parafilme }\end{array}$ & Algodão \\
\hline Ágar & $1,40 \mathrm{Aa}$ & $1,33 \mathrm{Aa}$ & $1,60 \mathrm{Aa}$ \\
Vermiculita & $1,53 \mathrm{Aa}$ & $1,40 \mathrm{Aa}$ & $2,73 \mathrm{Bb}$ \\
Plantmax $^{\circledR}$ & $1,13 \mathrm{Aa}$ & $1,40 \mathrm{Aa}$ & $2,66 \mathrm{Bb}$ \\
\hline
\end{tabular}

*Teste de Scott-Knott com significância de 5\%, médias seguidas de mesma letra, minúscula na coluna e maiúscula na linha, não diferem estatisticamente entre si.

Os tratamentos que empregaram tampa plástica e tampa plástica+parafilme no selamento não apresentaram diferença significativa no comprimento das folhas independente do substrato utilizado. O mesmo resultado foi observado para os tratamentos com ágar, independente do tipo de vedação. Nepomuceno et al. (2009) também observaram, em Angico-branco, folhas maiores e mais expandidas quando os tubos foram vedados com algodão.

O maior número de folhas contabilizadas nos tratamentos que empregaram tampa plástica na vedação pode estar relacionado a um processo de compensação em função das folhas apresentarem menor comprimento longitudinal. A utilização do algodão combinado com Plantmax ${ }^{\circledR}$ ou vermiculita mostrou-se mais promissora, uma vez que as características verificadas nesses tratamentos favoreceram o processo de aclimatização das plantas de Ipê-roxo.

Quanto aos aspectos nutricionais durante a aclimatização a ANAVA (Tabela 4), mostrou que as concentrações do meio MS influenciaram significativamente todas as variáveis analisadas.

As plantas irrigadas com solução MS, contendo $75 \%$ da sua concentração original, apresentaram melhor aspecto (nota média $=3$ ), não apresentando nenhum sintoma visual no crescimento ou nas folhas. Os demais tratamentos foram estatisticamente semelhantes entre si, ressaltando que as plantas com pior aspecto visual apresentaram notas inferiores a 2,28 (Figura 2). As mudas de Ipê-roxo, nesses tratamentos, apresentaram clorose e necrose foliar sendo que o tratamento controle também apresentou necrose apical e consequente quebra da dominância do ápice, o que ocasionou indução de brotações das gemas laterais em algumas plantas. 
Tabela 4 - ANAVA para aspecto sintomatológico nutricional (ASN), crescimento entre avaliações (CRES) e diferença no número médio de folhas entre avaliações (DNF).

Table 4 - ANAVA for nutritional symptomatological aspect $(A S N)$, growth in-between assessments (CRES) and difference in average number of leaves in-between assessments (DNF).

\begin{tabular}{lcccc}
\hline \multirow{2}{*}{ Fonte de Variação } & \multirow{2}{*}{$\begin{array}{c}\text { Grau de } \\
\text { Liberdade }\end{array}$} & \multicolumn{3}{c}{ Quadrado Médio } \\
\cline { 3 - 5 } & 5 & $0,75^{* *}$ & $2,19^{* *}$ & $3,50^{* *}$ \\
\hline Concentração & 24 & 0,14 & 0,00 & 0,00 \\
Erro & & 15,99 & 9,22 & 21,83 \\
Coeficiente de & & & & \\
Variação (\%) & & &
\end{tabular}

** Significativo ao nível de $1 \%$.

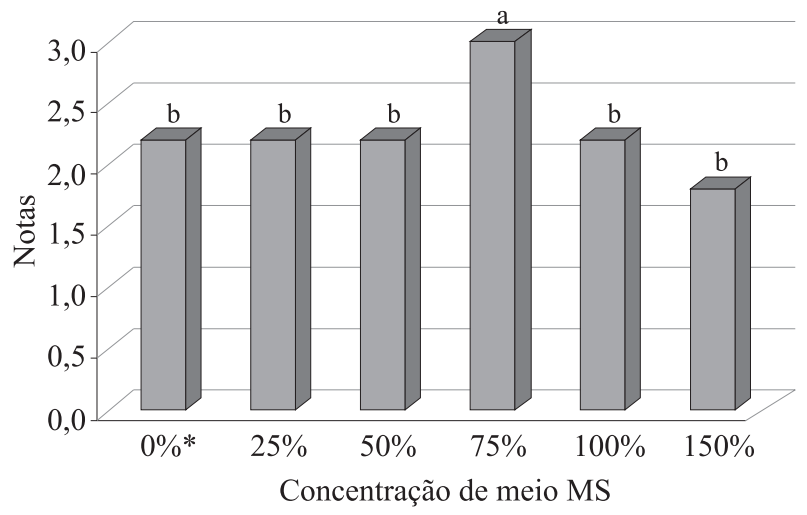

Figura 2 - Médias de notas para o aspecto sintomatológico nutricional de plantas de Ipê-roxo durante aclimatização. *Tratamento controle - água destilada. Letras diferentes diferem estatisticamente segundo teste de Scott-Knott ao nível 5\% de significância.

Figure 2 - Average score for nutritional symptomatological aspect of ipê-roxo plants during acclimatization. *Control treatment - distilled water. Different letters differ statistically by the Scott-Knott test at the 5\% significance level.

A sintomatologia observada nos tratamentos que empregaram concentrações iguais ou inferiores a 50\% da solução MS poderiam ser explicados pela deficiência de cálcio, magnésio, potássio, nitrogênio e boro. Os sintomas de deficiência ou excesso de um elemento mineral têm semelhança em todas as espécies de plantas (MEYER et al., 1983). Leal e Prado (2008) mencionam que a deficiência de nitrogênio compromete o crescimento e desenvolvimento das plantas, e a carência de potássio ao amarelecimento das bordas e clorose nas folhas mais velhas. Prado et al. (2007) afirmam que plantas com falta de cálcio e magnésio apresentam clorose internerval e necrose das regiões cloróticas; o que corrobora com os resultados obtidos neste trabalho. A deficiência de boro provoca desorganização do sistema vascular e, consequentemente, morte do meristema apical (SILVA et al., 2008), o que também foi observado no tratamento que utilizou água destilada na suplementação hídrica das plantas de Ipê-roxo.

Quando as plantas foram irrigadas com concentrações iguais ou superiores a $100 \%$ da solução MS foram averiguados sintomas semelhantes aos de deficiência observados anteriormente, porém esses sintomas podem ter sido ocasionados pelo acúmulo dos sais no substrato, o que impede a absorção de água e, consequentemente, diminuição da translocação dos nutrientes para planta (SILVA; AMORIN, 2009).

Cordão Terceiro Neto et al. (2004) observaram comportamento semelhante quando utilizaram altas concentrações de MS na aclimatização de plantas de violeta africana (Saintpaulia ionantha Wendl.).

Quando observado o crescimento no intervalo de avaliação verificou-se diferença significativa entre os tratamentos, sendo a maior média observada nas plantas irrigadas com a concentração $75 \%$ do meio MS (Tabela 5).

Tabela 5 - Média do crescimento no intervalo de avaliação de plantas de Ipê-roxo durante a aclimatização.

Table 5 -Average growth in the assessment interval of ipê-roxo plants during acclimatization.

\begin{tabular}{lc}
\hline Concentrações de meio MS & Crescimento $(\mathrm{cm})^{*}$ \\
\hline Água destilada & $0,20 \mathrm{e}$ \\
$25 \%$ & $0,37 \mathrm{~d}$ \\
$50 \%$ & $0,38 \mathrm{~d}$ \\
$75 \%$ & $1,57 \mathrm{a}$ \\
$100 \%$ & $1,27 \mathrm{~b}$ \\
$150 \%$ & $0,98 \mathrm{c}$ \\
\hline
\end{tabular}

*Letras diferentes diferem estatisticamente segundo teste de Scott-Knott ao nível 5\% de significância.

O tratamento controle apresentou variação negativa no crescimento, em razão da necrose apical provocada pela deficiência nutricional, diferente do averiguado nos outros tratamentos que apresentaram crescimento positivo. Cordão Terceiro Neto et al. (2004) verificaram maior altura em plantas de Violeta-africana quando irrigadas com baixas concentrações da solução MS

Cerne, Lavras, v. 17, n. 4, p. 435-442, out./dez. 2011 
durante a aclimatização, resultados estes que diferem dos observados neste trabalho, constatando maior necessidade de fornecimento de nutrientes durante a aclimatização para o Ipê-roxo.

A diferença do número médio de folhas entre as avaliações apresentou um comportamento quadrático significativo com o aumento da concentração da solução MS (Figura 3).

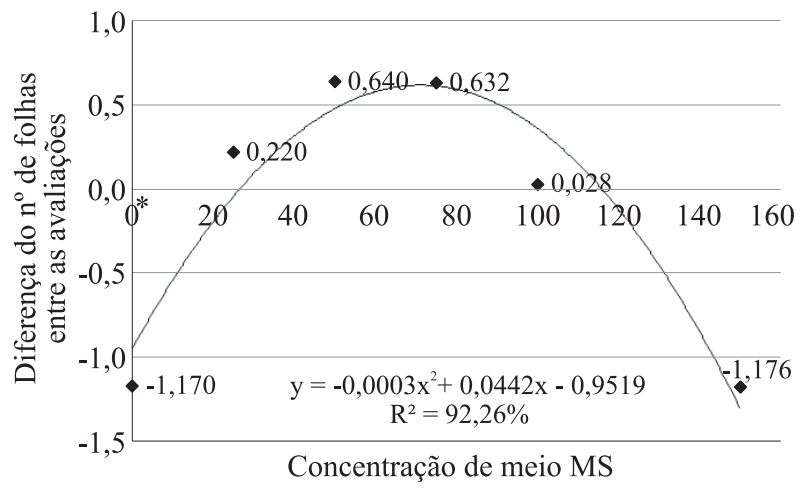

Figura 3 - Efeito da concentração de meio MS sobre a diferença do número médio das folhas de Ipê-roxo entre as avaliações temporais. *Tratamento controle - água destilada. Significância de 5\%.

Figure 3 - Effect of MS medium concentration on the difference in average number of leaves for ipê-roxo in-between assessments. *Control treatment - distilled water. 5\% significance.

As plantas irrigadas com água destilada (isenta de nutrientes) e com a concentração $150 \%$ de MS obtiveram as menores médias para o número de folhas, o que pode ter ocorrido, em decorrência da abscisão foliar intensa nesses tratamentos, diferente do observado nos outros tratamentos. Resultados semelhantes foram obtidos por Skrebsky et al. (2008), em experimento com aclimatização de Ginseng brasileiro (Pfaffia glomerata), no qual observaram que a deficiência de nutrientes como $\mathrm{Mg}, \mathrm{Ca}$, $\mathrm{P}$ e K influenciou o número de folhas, tendo o tratamento com água destilada apresentado a menor média.

\section{CONCLUSÕES}

Na pré-aclimatização de Ipê-roxo recomenda-se utilizar o tipo de vedação algodão com substrato Plantmax ${ }^{\circledR}$ ou vermiculita.

A concentração de meio de cultivo MS $75 \%$ foi a mais eficiente no crescimento de mudas de Ipê-roxo em processo de aclimatização.

Cerne, Lavras, v. 17, n. 4, p. 435-442, out./dez. 2011

\section{REFERÊNCIAS}

BELLINTANI, M. C.; LIMA, C. C.; BRITO, A. L.; SANTANA, J. R. de; DORNELLES, A. L. C. Efeito da ventilação in vitro na aclimatização de plantas micropropagadas de Orthophytum mucugense Wand e Conceição. Revista Brasileira de

Biociências, Porto Alegre, v. 5, n. 2, p. 1098-1100, 2007.

CORDÃO TERCEIRO NETO, C. P.; HERNANDEZ, F. F. F.; BEZERRA, F. C.; SOUSA, R. F. de; CAVALCANTTI, M. L. F. Efeito da concentração salina da solução nutritiva na aclimatação de plantas micropropagadas de Violeta Africana (Saintpaulia ionantha Wendl). Revista de Biologia e Ciências da Terra, Campina Grande, v. 4, n. 2, p. 1-9, 2004.

COSTA, E.; RODRIGUES, E. T.; ALVES, V. B.; SANTOS, L. C. R. dos; VIEIRA, L. C. R. Efeitos da ambiência, recipientes e substratos no desenvolvimento de mudas de Maracujazeiroamarelo em Aquidauana, MS. Revista Brasileira

Fruticultura, Jaboticabal, v. 31, n. 1, p. 236-244, 2009.

DAMIANI, C. R.; SCHUCH, M. W. Enraizamento in vitro de mirtilo em condições fotoautotróficas. Ciência Rural, Santa Maria, v. 39, n. 4, p. 1012-1017, 2009.

FERREIRA, D. F. SISVAR 4.3 sistema de análises estatísticas. Lavras: UFLA, 1999.

GEMAQUE, R. C. R.; DAVIDE, A. C.; FARIA, J. M. R. Indicadores de maturidade fisiológica de sementes de IpêRoxo (Tabebuia impetiginosa (Mart.) Standl.). Cerne, Lavras, v. 8, n. 2, p. 84-91, 2002.

GROSE, S. O.; OLMSTEAD, R. G. Taxonomic revisions in the polyphyletic genus Tabebuia s. 1. (Bignoniaceae). Systematic Botany, Laramie, v. 32, n. 3, p. 660-670, 2007.

HARARIKA, B. N. Acclimatization of tissue-cultured plants. Current Science, Stanford, v. 85, n. 12, p. 1704-1712, 2003.

LEAL, R. M.; PRADO, R. de M. Desordens nutricionais no feijoeiro por deficiência de macronutrientes, boro e zinco.

Revista Brasileira de Ciências Agrárias, Recife, v. 3, n. 4, p. 301-306, 2008.

LLOYD, G.; MCCOWN, B. Commercially feasible micropropagation of montain laurel, Kalmia latifolia, by use of shoot tip culture. Combined Proceedings of the International Plant Propagator's Society, Carlisle, v. 30, p. 421-327, 1981. 
LUCAS, M. A. K.; SAMPAIO, N. V.; KOHN, E. T.; SOARES, P. F.; SAMPAIO, T. G. Avaliação de diferentes composições de substratos para a aclimatação de mudas de morangueiro (Fragaria x Ananassa Duch). Ciência Rural, Santa Maria, v. 8, n. 1, p. 16-23, 2002.

MEYER, B.; ANDERSON, D.; BOHNING, R.; FRATIANNE, D. Introdução à fisiologia vegetal. 2. ed. Lisboa: Fundação Calouste Gulbenkian, 1983. 710 p.

MILLS, D.; YANQING, Z.; BENZIONI, A. Improved of jojoba shoot multiplication in vitro by ventilation. In Vitro Cellular \& Developmental Biology Plant, Wallingford, v. 40, n. 4, p. 396-402, 2004.

MURASHIGE, T.; SKOOG, F. A revised medium for rapid growth and bioassays with tobacco tissue cultures. Physiologia Plantarum, Copenhagen, v. 15, p. 473-497, 1962.

NASCIMENTO, A. da C.; PAIVA, R.; ABBADE, C. L.; VARGAS, D. P.; SOARES, F. P. Micropropagação de Uvaieira (Eugenia pyriformis Cambess): efeitos do BAP e AIB. Revista Verde, Mossoró, v. 3, n. 2, p. 20-26, 2008.

NEPOMUCENO, C. F.; RIOS, A. P. de S.; QUEIROZ, S. R. de O. D.; PELACANI, C. R. P.; SANTANA, J. R. F. de. Respostas morfofisiológicas in vitro de plantas de Anadenanthera colubrina (Vell.) Brenan var. cebil (Griseb) Altschul. Revista Árvore, Viçosa, v. 33, n. 3, p. 481-490, 2009.

NOGUEIRA, R. C.; PAIVA, R.; OLIVEIRA, L. M. de; SOARES, G. de A.; SOARES, F. P.; CASTRO, A. H. F.; PAIVA, P. D. de O. Indução de calos em explantes foliares de Murici-pequeno (Byrsonima intermedia A. Juss.). Ciência e Agrotecnologia, Lavras, v. 31, n. 2, p. 366-370, mar./abr. 2007.

PEREIRA, J. E. S.; FORTES, G. R. de L. Desfolhamento e baixa temperatura em plantas micropropagadas de macieira como forma de superar a parada de crescimento durante a aclimatização. Revista Brasileira de Fisiologia Vegetal, Lavras, v. 12, n. 2, p. 135-145, 2000.

PEREIRA, J. E. S.; FORTES, G. R. de L. Multiplicação e aclimatização da macieira influenciada pelo tipo de explante e pelo tempo de permanência em meio de cultura de enraizamento. Revista Brasileira de Fruticultura, Jaboticabal, v. 23, n. 2, p. 417-420, 2001.
PEREIRA, J. E. S.; FORTES, G. R. de L.; SILVA, J. B. da. Efeito da aplicação de baixa temperatura em plantas de macieira sobre o crescimento durante a aclimatização. Pesquisa Agropecuária Brasileira, Brasília, v. 36, n. 1, p. 89-95, 2001.

PEREIRA, M. C. T.; NIETSCHE, S.; FRANÇA, A. C.; NUNES, C. F.; LIMA, C. de; GONÇALVES, V. D.; SALLES, B. P.; MORAIS, D. L. B.; KOBAYASHI, M. K. Aclimatização de mudas micropropagadas de Bananeira sob diferentes condições de luminosidade. Revista Brasileira de Fruticultura, Jaboticabal, v. 27, n. 2, p. 238-240, 2005.

PRADO, R. de M.; ROMUALDO, L. M.; ROZANE, D. E. Omissão de macronutrientes no desenvolvimento e no estado nutricional de plantas de sorgo (cv. BRS 3010) cultivadas em solução nutritiva. Científica, Jaboticabal, v. 35, n. 2, p. 122128, 2007.

SARASAN, V.; CRIPPS, R.; RAMSAY, M. M.; ATHERTON, C.; MCMICHEN, M.; PRENDERGAST, G.; ROWNTREE, J. K. Conservation in vitro of threatened plants: progress in the past decade. In vitro Cellular \& Developmental Biology Plant, Wallingford, v. 42, n. 3, p. 206-214, 2006.

SILVA, D. H. da; ROSSI, M. L.; BOARETTO, A. E.; NOGUEIRA, N. de L.; MURAOKA, T. Boron affects the growth and ultrastructure of castor bean plants. Scientia Agricola, Piracicaba, v. 65, n. 6, p. 659-664, 2008.

SILVA, M. G.; AMORIM, S. M. C. de. Estresse salino em plantas de Spondias tuberosa arruda (Câmara) colonizadas com fungos micorrízicos arbusculares. Revista Caatinga, Mossoró, v. 22, n. 2, p. 91-96, 2009.

SKREBSKY, E. C.; NICOLOSO, F. T.; MALDANER, J.; RAUBER, R.; CASTRO, G. Y.; JUCOSKI, G. de O.; SANTOS, D. R. dos. Caracterização das exigências nutricionais de mudas de Pfaffia glomerata em Argissolo Vermelho distrófico arênico pela técnica do nutriente faltante. Ciência Rural, Santa Maria, v. 38, n. 4, p. 989-996, 2008.

SMIDERLE, O. J.; SALIBE, A. B.; HAYASHI, A. H.; MINAMI, K. Produção de mudas de alface, pepino e pimentão em substratos combinando areia, solo e Plantmax ${ }^{\circledR}$. Horticultura Brasileira, Brasília, v. 19, n. 3, p. 253-257, 2001 .

Cerne, Lavras, v. 17, n. 4, p. 435-442, out./dez. 2011 
VILLA, F.; PASQUAL, M.; ARAÚJO, A. G.; PIO, L. A. S. Micropropagação da amoreira-preta (Rubus spp.) e efeito de substratos na aclimatização de plantas. Acta $S$ cientiarum Agronomy, Maringá, v. 28, n. 1, p. 47-53, 2006.
ZOBAYED, S. M. A.; AFREEN-ZOBAYED, F.; KUBOTA, C.; KOZAI, T. Mass propagation of Eucalyptus camaldulensis in a scaled-up vessel under in vitro photoautotrophic condition. Annals of Botany, London, v. 85, n. 5, p. 587-592, 2000.

Cerne, Lavras, v. 17, n. 4, p. 435-442, out./dez. 2011 